\title{
Psicoterapia Breve Operacionalizada e crise por expectativa de perda: Um estudo de caso
}

\author{
Operationalized Short Term Therapy and crisis by \\ expectation of loss: A case study
}

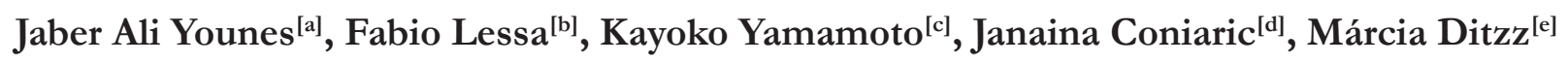

[a] Psicólogo, Mestrando em Psicologia Clínica, Universidade de São Paulo (USP), pesquisador bolsista do CNPq, São Paulo, SP Brasil, e-mail: jaber@usp.br

[b] Psicólogo da rede pública hospitalar, São Paulo, SP - Brasil, e-mail: lessafabio@ig.com.br

[c] Professora Doutora do Instituto de Psicologia da Universidade de São Paulo (IPUSP), coordenadora do curso de Especialização em Psicoterapia Psicanalítica do Instituto de Psicologia da Universidade de São Paulo (IPUSP), São Paulo, SP - Brasil, e-mail: kayamato@terra.com.br

[d] Psicóloga, Mestranda em Psicologia Clínica pela Universidade de São Paulo (USP), Especialista em Psicanálise da Criança, Instituto Sedes Sapientiae, São Paulo, SP - Brasil, e-mail: jan.coniaric@usp.br

[e] Psicóloga, São Paulo, SP - Brasil.

\section{Resumo}

O presente artigo propõe ilustrar o tratamento de um paciente em situação de crise por expectativa de perda com a utilização do método da Psicoterapia Breve Operacionalizada (PBO). A partir de um estudo de caso, aplicou-se a Escala Diagnóstica Adaptativa Operacionalizada (EDAO) como instrumento diagnóstico, no início e no fim da $\mathrm{PBO}$ de uma paciente. $\mathrm{O}$ arsenal conceitual e instrumental constitutivos da EDAO e da PBO demonstrou relevante importância na prática da psicoterapia breve, uma vez que oferece meios de identificar e atuar com eficiência em situações em que a paciente experimentava crise por expectativa de perda. A técnica utilizada possibilitou o atendimento em suas necessidades emergenciais, o que resultou na redução da intensidade da crise. A ajuda pontual e focada na situação de crise permitiu que a paciente pudesse fazer uso de seus recursos elaborativos, sem se precipitar numa atuação destrutiva que poderia colocar em risco a realização de seu desejo.

Palavras-chave: Psicoterapia Breve Operacionalizada (PBO). Escala Diagnóstica Adaptativa Operacionalizada (EDAO). Teoria da Adaptação. Psicanálise. Crise adaptativa. 


\begin{abstract}
This article proposes to illustrate the treatment procedure within a case of expectation of loss, based on theoretical reference of Operationalized Short Term Therapy (OSTT). From a case study, Operationalized Adaptative Diagnostic Scale (OADS) was applied as a diagnostic tool at the beginning and at the end of patient's treatment. The conceptual and instrumental arsenal that constitutes OADS and OSTT showed relevant importance on the practice of short term psychotherapy, since it provides means to identify and act effectively in situations where the patient is experiencing crisis by expectation of loss. This technique allowed the care in her emergency needs, resulting in the reduction of the crisis intensity. The aid focused on the crisis allowed the patient to make use of its elaborative resources, without rushing into a destructive action that could endanger the accomplishment of its desire.
\end{abstract}

Keywords: Operationalized Short Term Therapy. Operationalized Adaptative Diagnostic Scale. Adaptation Theory. Psychoanalysis. Adaptative crisis.

\section{Introduçáo}

Em qualquer momento da vida, uma pessoa pode se deparar com situações novas causadoras de intenso sofrimento, como morte em família, perda de emprego, separação no casamento, ascensão profissional, nascimento de um filho, entre outras. Tais situações, dependendo do significado emocional que a pessoa atribui à experiência, podem gerar crises adaptativas (Simon, 1989). O presente artigo pretende abordar uma crise situada nesse contexto, mais especificamente uma crise gerada por expectativa de perda (Simon, 1989), e as contribuições da Psicoterapia Breve Operacionalizada (PBO) (Simon, 2005), como instrumento terapêutico, em seu desfecho.

Muitos autores apresentaram importantes concepções de crise. Segundo Erickson (1959), uma crise pode compreender duas classificações: crise de desenvolvimento, proveniente das etapas naturais do processo de desenvolvimento; e crise acidental, incitada por acontecimentos ocasionais na vida do indivíduo. Para Caplan (1964), crise refere-se a um período de perturbação emocional comintensidade suficiente paradesestabilizar o equilíbrio psicológico do indivíduo, quando a solução parao "problema" nãoé encontrada no tempo habitual. Já para Moffatt (1982), mais significativo que o trauma sofrido pela pessoa é o inesperado dessa nova situação. O paciente percebe o episódio como algo irreal, pois até então não havia concebido algo semelhante em suas fantasias para o futuro. Entre nós, Hegenberg (2004) entende por crise uma interrupção do equilíbrio, um corte na subjetividade, uma rupturano sentido devida.E Simon (1989, p. 60) descreve a crise como sendo gerada por acontecimentos internos ou externos ao indivíduo e que ocorrem de forma abrupta, configurando-se em "uma situaçãonova, vitalmente transformadora", capaz de propiciar, momentaneamente, a falta de respostasolução. Tais acontecimentos provocam "um aumento ou redução significativa do espaço nouniverso pessoal".

Muitas contribuições para o estudo de intervenções em crise foram publicadas. Sifneos (1989, 1993) observou em seu trabalho que pacientes em estado de crise psicológica necessitam de um tipo diferente de intervenção, que ofereça assistência imediata e lhes permita superar a crise e retornar ao estado de equilíbrio emocional que existia antes do início dela. Nesse sentido, Malan $(1976,1979)$ enfatiza a possibilidade de efeito máximo que uma intervenção pode alcançar em um paciente em crise, dada a motivação deste em receber ajuda especializada. A importância do pronto atendimento pode ser constatada em crises decorrentes de traumas psicológicos, como a violência sexual contra a mulher. A mulher vítima de estupro, ao ser atendida prontamente e com atitudes de apoio, respeito e sensibilidade por parte do profissional, tem uma recuperação mais eficaz (Faundes, Rosas, Bedone \& Orozco, 2006).

Bellak e Small (1978) afirmam que muitas pessoas procuram psicoterapia somente quando estão em crise. Uma vez passada a crise, a motivação para continuar uma exploração em profundidade compreensão de conflitos inconscientes, dificuldades outras existentes ou até uma reestruturação da personalidade - diminui ou desaparece. Para os autores, é necessário que o psicoterapeuta seja responsável pela ajuda a pessoas, da forma mais eficiente possível, mas dentro dos limites de suas motivações e de suas 
disponibilidades para receber as intervenções terapêuticas, e que, para tanto, é preciso ouvir o paciente e oferecer aquilo que ele necessita. Quanto a Sifneos (1989, 1993), este nos diz que o entendimento de uma crise emocional elucida os diferentes estados de formação dos sintomas psiquiátricos, o que, por sua vez, permite a execução de medidas preventivas que concorrem para a interrupção de seu agravamento, entre as quais as intervenções psicoterápicas breves. A esse respeito, Gebara (2003) diz que a psicoterapia breve está relacionada a situações de crise, momentos em que a pessoa, não tendo condições de lidar sozinha com os problemas que a afetam, encontra-se fragilizada e, por isso, mais motivada para mudanças, oferecendo maiores possibilidades de intervenção.

Os estudos anteriormente mencionados apontam para um consenso em que a psicoterapia breve é a modalidade terapêutica mais indicada na intervenção em crise. Ela oferece, também, contribuição para uma importante questão de nossa sociedade atual: o envelhecimento da população mundial. Altman, Yamamoto e Tardivo (no prelo) referem, no artigo que tem como tema o atendimento em $\mathrm{PBO}$ a uma paciente idosa, a vivência de sofrimento e desamparo que estaria afetando essa população. Eles refletem a respeito da discriminação e preconceito da sociedade em relação ao status negativo de sua condição, além do descaso do poder público em suas políticas de proteção social para a terceira idade, fatores que contribuem para a ocorrência de crises adaptativas, principalmente quando relacionadas a perdas ou ameaça de perdas afetivas e/ou materiais. Oliveira (2001) verificou que pacientes com hipertensão essencial puderam ser beneficiados com a prática da Psicoterapia Breve Operacionalizada. As alterações observadas nesses pacientes, após serem submetidos a essa modalidade terapêutica, relacionaram-se principalmente à flexibilização dos mecanismos de defesa e abrandamento na severidade do superego, constatadas a partir de melhor percepção de si e do contato com as pessoas mais próximas afetivamente. Alves (2001) oferece uma contribuição à Psicologia Clínica Preventiva com sua tese de doutorado, em que investiga a eficácia da PBO com adolescentes da rede pública escolar da cidade de Santos, SP.

Desse modo, diante de tantas possibilidades de psicoterapias breves, optamos pela Psicoterapia Breve Operacionalizada, que, por ser derivada da Teoria da Adaptação (que será vista mais adiante), não faz uso de critérios restritivos na seleção de pacientes, como os modelos propostos por Malan (1976, 1979) ou Sifneos (1989, 1993): inteligência acima da média, capacidade para "insight", presença de quadros psicopatológicos, entre outros, pois esses critérios iriam excluir parcela significativa da população geral. Entretanto, não são indicados para a Psicoterapia Breve Operacionalizada pessoas que buscam o autoconhecimento (cuja indicação seria uma análise) ou mudanças em traços de personalidade (objetivo da psicoterapia psicanalítica).

\section{Psicologia Clínica Preventiva e Teoria daAdaptação}

A Psicologia Clínica Preventiva vem se desenvolvendo no campo da pesquisa e prática para, cada vez mais, poder beneficiar a população como um todo, a partir da aplicação dos princípios preventivos quanto à instalação de conflitos emocionais e tratamento para os já existentes, a fim de limitar seu agravamento e evitar possíveis sequelas incapacitantes.

Precursor no campo da Psicologia Clínica Preventiva, Simon (1989) traz inúmeros trabalhos e contribuições que viabilizam a prática da prevenção. Dentre eles, a formulação do conceito de adaptação, que fundamenta a Teoria da Adaptação por ele desenvolvida. Esse construto teórico afirma que todos os seres vivos - inclusive os humanos - conquistaram algum grau de adaptação, por mínima que seja, compatível com a vida. Donde se conclui que, sem adaptação, não há vida. A teoria adaptativa traz ainda que a adaptação, a partir de critérios de adequação, pode ser avaliada como sendo eficaz ou ineficaz, e está subdividida em quatro categorias: leve, moderada, severa e grave. Diz também que todo o comportamento pode ser compreendido e classificado conforme o referencial adaptativo, de acordo com as variações que sofre em sua eficácia em decorrência das circunstâncias internas e externas à pessoa.

\section{Escala Diagnóstica Adaptativa Operacionalizada (EDAO)}

Na década de 1970, Simon (1989), por meio dos fundamentos de sua Teoria da Adaptação e visando à implantação, com a população universitária da Escola Paulista de Medicina (atual UNIFESP), de um programa de prevenção secundária dos distúrbios 
mentais - fase da prevenção em que o problema já está instalado e se procura evitar seu agravamento para evitar a cronificação e/ou incapacitação (Leavell e Clarck, 1965)-, criou a chamada Escala Diagnóstica Adaptativa Operacionalizada (EDAO). O autor considerava que as classificações diagnósticas existentes, baseadas em sintomas psicopatológicos, seriam de pouca utilidade para as finalidades preventivas que pretendia alcançar. Isso porque a população universitária era constituída por jovens que, em sua maioria, se encontravam saudáveis física e psicologicamente, pouco passíveis de se enquadrar em qualquer uma das classificações diagnósticas tradicionais.

Assim Simon justifica a criação da EDAO:

Na prática da prevenção seria desejável uma escala diagnóstica menos sofisticada e complexa para: a) apressar a classificação dos indivíduos da população - poupando tempo do entrevistador e assim aumentando seu rendimento para abranger maior número; $b$ ) deixar poucos casos sem classificação definida desde o início; c) sendo mais simples e operacionalizada, melhorar o consenso entre os avaliadores do diagnóstico; e, o que é mais importante, na prática; d) instrumentar o encaminhamento de cada sujeito diagnosticado segundo as várias fases da prevenção (Simon, 1989, p. 14).

A EDAO possibilita a classificação das pessoas quanto à eficácia de sua adaptação, como dito anteriormente, em cinco grupos:

- Grupo 1-Adaptação eficaz: personalidade "normal", raros sintomas neuróticos ou caracterológicos;

- Grupo 2 - Adaptação ineficaz leve: sintomas neuróticos brandos, ligeiros traços caracterológicos, algumas inibições;

- Grupo 3 - Ineficaz moderada: alguns sintomas neuróticos, inibição moderada, alguns traços caracterológicos;

- Grupo 4 - Adaptação ineficaz severa: sintomas neuróticos mais limitadores, inibições restritivas, rigidez de traços caracterológicos; - Grupo 5 - Adaptação ineficaz grave: neuroses incapacitantes, borderlines, psicóticos não agudos, extrema rigidez caracterológica (Simon, 2005, p.28).
A classificação das pessoas nesses cinco grupos resultará da avaliação de suas respostas, de acordo com os seguintes critérios:

a) solução do problema;

b) se a solução é gratificante ou não;

c) se a solução gera ou não conflitos intrapsíquicos ou ambientais.

1) Setor afetivo-relacional (A-R): compreende o conjunto dos sentimentos, atitudes e ações do sujeito em relação a si mesmo (intrapessoal) eao semelhante (interpessoal);

2) Setor produtividade $(\mathbf{P r})$ : refere-se ao conjunto de sentimentos, atitudes e ações da pessoa em face ao trabalho, estudo, ou qualquer atividade produtiva, seja de natureza artística, filosófica ou religiosa, considerada como atividade principal no período considerado.

3) Setor sócio-cultural (S-C): abrange o conjunto dos sentimentos, atitudes e ações do indivíduo relativos à organização social, recursos comunitários, pressões sociais, bem como aos valores e costumes da cultura em que vive;

4) Setor orgânico (Or): compreende a salubridade, o estado (anatômico) e o funcionamento (fisiológico) da totalidade do organismo da pessoa, bem como seus sentimentos, atitudes e ações em relação ao próprio corpo, à higiene, alimentação, sono, sexo (fisiológico), indumentária (Simon, 2005, p. 25).

Em 1998, houve uma redefinição da EDAO. Os setores afetivo-relacional e produtividade, considerados clinicamente mais importantes, foram mantidos com atribuições qualitativas e quantitativas, e os setores sócio-cultural e orgânico, somente qualitativas.

\section{Psicoterapia Breve Operacionalizada (PBO)}

Por meio da aplicação e análise da EDAO em grupos de supervisão para discussão diagnóstica, Simon (1996) se deu conta de sua aplicabilidade na estruturação de um modelo de psicoterapia breve. Dentre os setores adaptativos já mencionados, reconheceu-se a posição central do afetivo-relacional 
(AR), e a partir deste, uma multiplicidade de interações com os outros setores. Este raciocínio clínico facilita o rastreamento das situações-problema e o ordenamento das prioridades no planejamento de uma psicoterapia breve, que, segundo o autor, é a forma de ajuda mais indicada em uma situação de crise adaptativa.

Partindo dessas premissas, inicia-se a PBO com entrevistas psicológicas, em que se investiga a situação atual e a história pregressa do paciente. Nesse período, a quantidade de entrevistas variará de acordo com a especificidade de cada caso, visto que quanto mais abrangente for a investigação inicial, maior será a possibilidade de circunscrever a situação-problema de forma clara e precisa. Busca-se abarcar os setores afetivo-relacional, produtividade, orgânico e sóciocultural, com o intuito de verificar as adequações do sujeito no presente e, assim, circunscrever a situaçãoproblema. Entende-se por situação-problema as soluções pouco ou pouquíssimo adequadas verificadas nos setores adaptativos. Se houver mais de uma situaçãoproblema, determina-se qual a situação nuclear. Em um segundo momento, nessas mesmas entrevistas procura-se acompanhar a evolução do sujeito desde a infância até o presente, conforme suas soluções e relacionamentos nos quatro setores adaptativos. Simon diz que a partir desse histórico é possível conjecturar a respeito da dinâmica inconsciente e a construção de seus complexos inconscientes que influenciam, na maioria das vezes, as soluções pouco ou pouquíssimo adequadas na atualidade. Em seguida, de posse das informações sobre a situação-problema, adequação atual e conjecturas psicodinâmicas, o psicoterapeuta determina previamente o número de sessões a serem trabalhadas com o paciente. Em casos de crise, o autor recomenda o número máximo de 12 sessões, com frequência de uma vez por semana.

A postura do psicoterapeuta na PBO é diretiva, evita que o paciente faça associações livres prolongadas, e utiliza a interpretação teorizada. Este conceito diz respeito à interpretação fundamentada no conhecimento da história do paciente - adquirido a partir das entrevistas iniciais - e sobre o qual aplicase a teoria psicanalítica dos dinamismos inconscientes originados nas relações com pessoas significativas da infância, ou na fantasia. As situações-problema são trabalhadas por meio de interpretações teorizadas e clarificações, almejando que o paciente compreenda as soluções pouco e pouquíssimo adequadas que utiliza.

Outro conceito que Simon (2001) formula em seus anos de experiência em psicoterapia psicanalítica, e que tem igual importância no manejo da PBO, é o da cotranferência. Esta seria a transferência experienciada com outras pessoas que não o terapeuta e do momento atual. E completa: "Portanto, por reconhecer a importância das transferências com pessoas outras que não o terapeuta, e facilitar a comunicação, proponho chamar essas transferências colaterais abreviadamente de "cotransferências"” (grifos do autor, p. 7).

Nos casos de crise usam-se ainda outras intervenções suportivas (Wolberg, 1967), como o reasseguramento e a orientação. Busca-se, por meio de atitude respeitosa e cortês, estimular a transferência positiva; por outro lado, evita-se a transferência negativa, mas caso surja, é necessário que seja trabalhada em termos de situação real no "aqui-agora" com o terapeuta, afim de que o paciente colabore e confie no profissional, objetivando o melhor resultado possível dentro do planejamento previsto.

Simon e Yamamoto (no prelo) lembram que esse tipo de intervenção pode contribuir, por outro lado, para a criação de soluções que possam transformar um momento de crise em possibilidade de crescimento da maturidade emocional.

\section{Teoria da crise}

A partir de sua Teoria da Adaptação, Simon (1989) classifica crise de acordo com sua etiologia: por perda ou ameaça de perda, e ganho ou expectativa de ganho. Essa crise abala o equilíbrio adaptativo, em função de redução ou aumento significativo do espaço no universo pessoal do paciente. $\mathrm{O}$ autor, associando sua teoria com significados psicodinâmicos, afirmou:

Igualando os fatores de crise às pressões internas ou externas extremas, supomos que os sentimentos de intensa angústia, às vezes de pânico, que assaltam o sujeito em crise, não seriam devidos apenas à falta de solução para o novo, mas à projeção e identificação do novo com fantásticas ameaças provocadas pelas figuras aterrorizantes das camadas do inconsciente que emergem nestes estados de extrema tensão emocional (Simon, 1989, p. 60).

Conforme a classificação da crise verifica-se sentimentos predominantes, o que determina procedimentos preventivos específicos a cada tipo de crise: 
1) crises por perda significativa ou ameaça de perda: diante de fortes sentimentos predominantes de depressão e culpa, há risco de autoagressão, automutilação, suicídio, projeção da culpa em outrem. Alguns exemplos destas situações: separações conjugais, violência sexual, doenças graves, desastres, inundações, incêndios, comunidades residentes em áreas de risco, perda de pessoas próximas por causa da violência urbana;

- Objetivo preventivo: “aceitar a perda, reinteressar-se pelo universo pessoal e lidar com sentimentos predominantes" (Simon, 1989, p. 62);

2) crises por aquisição ou por expectativa de aquisição: diante de sentimentos predominantes como insegurança, inferioridade ou inadequação, pode ocorrer abandono direto ou indireto do ganho no universo pessoal do paciente, por não saber como lidar com determinada questão. Pacientes podem admitir mais responsabilidade do que realmente são capazes de assumir, o que pode ocasionar problemas de ordem psicossomática, como depressão, problemas relacionados à obesidade, úlcera, tendinite, além de outras situações incapacitantes. Dois exemplos podem ser a promoção no emprego, ou uma gravidez inesperada.

-Objetivo preventivo:" aceitar(ou renunciar) o ganho realisticamente e lidar com os sentimentos predominantes" (Simon, 1989, p. 62).

\section{Atendendo em psicoterapia breve operacionalizada}

Com o objetivo de ilustrar situação de crise atendida pelo método da $\mathrm{PBO}$, será apresentado o caso de atendimento de Maria, como a chamaremos, uma paciente de 45 anos.

\section{Compreensáo psicodinâmica e adaptativa do caso}

Motivo da consulta: Maria queixou-se de cansaço, taquicardia, falta de ar, tremores pelo corpo, dores no ombro e pescoço, além de uma "ansiedade" (sic). Ela havia sido atendida por psiquiatra, que a medicou com antidepressivo e a encaminhou para psicoterapia. Apesar de medicada, seu desconforto subjetivo ainda persistia. Durante a primeira entrevista manifestava ansiedade, que se percebia pela respiração ofegante, voz trêmula e agitação nas mãos, cutucando com os dedos de uma mão os dedos da outra. Vestia-se com simplicidade e asseio na aparência.

Orientado pelo pressuposto da "causalidade necessária” (Simon, 2005, p. 100), em que, de acordo com Simon, referindo-se ao determinismo psíquico explicitado por Freud, "o terapeuta tem de admitir por princípio que não existe efeito sem causa", o psicólogo pôs-se a investigar quais circunstâncias poderiam ter precipitado o quadro sintomático acima descrito. Sem hesitar, Maria contou que há dois meses mantém um caso amoroso com seu chefe, às ocultas, posto que ele não queria assumir o romance publicamente. Em razão de motivos que logo serão descritos, Maria temia que a relação terminasse. Concluída a investigação da queixa, o entrevistador procurou recolher as informações referentes aos quatro setores adaptativos: afetivo-relacional (A-R), produtividade $(\mathrm{Pr})$, sócio-cultural (S-C) e orgânico (Or). Uma vez extraídos os dados considerados suficientes para compreensão do caso e elaboração do diagnóstico adaptativo, passou-se a avaliar sua adequação setorial (Simon, 1989). No afetivo-relacional, o conjunto de soluções indicava que estava pouco-adequada, pois, mesmo envolvida num romance que desejava, experimentava estado de ansiedade conjugado a um quadro sintomático que, embora estivesse presente desde o início da relação, intensificou-se após sentir a ameaça de que esse romance pudesse findar. Assim, estava frustrada em seu desejo de afeto. Consideramos sua adequação nesse setor como pouco-adequada. Quanto à produtividade, sua solução era adequada. Trabalhava um dia da semana como empregada num casarão que funcionava como hotel, dois dias como doméstica noutro lugar; além de cuidar da própria casa. Relatava sentir "cansaço" após uma jornada diária de trabalho. Não obstante, afirmava gostar do que fazia e ressaltava que seu trabalho lhe proporcionava uma renda que antes não tinha, e que, em função disso, deixava-a com menos dificuldades. No sócio-cultural não havia indicativos de conflitos com os valores e costumes de seu ambiente. Frequentava semanalmente igreja, de onde extraía conforto e tranquilidade, além de manter e ampliar seus laços 
sociais. Nesse setor encontrava-se adequada. Por fim, embora cuidasse da aparência e da alimentação e de manter uma vida sexual ativa e satisfatória, além dos sintomas somáticos, apresentava dificuldades para conciliar o sono. Assim, no setor orgânico foi considerada pouco adequada.

Ao todo, foram realizadas quatro entrevistas diagnósticas. $\mathrm{Na}$ terceira entrevista, Maria mal acabara de adentrar a sala e se acomodar à cadeira, foi logo contando que seu par romântico "pediu um tempo" - o que concretizou sua expectativa ansiosa, presente desde o início do romance, de que a relação pudesse terminar. Após refletir, pensou que esse pedido dever-se-ia a que ele se assustara com algumas de suas atitudes. De fato, a paciente pouco controlava seus impulsos e muitas vezes deixava às claras seu ciúme e hostilidade para com as rivais que encontrava no caminho. Essas rivais, que eram as outras funcionárias que trabalhavam no casarão, também a hostilizavam. Essa configuração caracterizava um conflito externo que constituía uma ameaça para a continuidade do romance, já que seu parceiro dizia categoricamente que não queria que a relação se tornasse pública; agindo assim, ela estaria colocando em risco a condição de mantê-la secreta. Face à angústia da paciente, o psicólogo adota medidas suportivas (Wolberg, 1967). Sugere, prematuramente, que 'pedir um tempo' não significava que ele não queria mais se envolver. Essa sugestão foi precipitada: e se realmente ele não quisesse mais seguir com o enlace amoroso? Caso isso acontecesse, a confiança da paciente no psicólogo estaria abalada e, consequentemente, o transcorrer da psicoterapia. Enfim, conclui sua sugestão pontuando que ela deveria ter paciência e esperar as tensões se aplacarem. Essa intervenção, embora arriscada, a aliviou e devolveu a esperança de, em breve, reatar o romance, pois observou que faria o esforço de manter seus impulsos sob domínio. No encontro seguinte, já bem mais tranquila, foi possível continuar a investigação, uma vez que seu estado de ansiedade aguda cedeu, permitindo à paciente colaborar e fornecer os dados restantes. Aliás, demonstrou ligeiro contentamento, contando, com sorriso nos lábios, que haviam reatado o romance e que seu parceiro a elogiou por estar mais controlada. Enfim, a fase inicial da PBO foi concluída com mais duas entrevistas diagnósticas.

Analisada a adequação em todos os setores, estabeleceu-se o seguinte diagnóstico adaptativo:
Grupo 2, adaptação ineficaz leve, em crise por expectativa de perda.

A situação-problema eleita para ser trabalhada durante a PBO é exatamente sua crise por expectativa de perda, traduzida no temor de que seu parceiro decidisse romper o romance que ela tanto desejava manter. Optou-se por 12 sessões, considerado o número máximo para pacientes que enfrentam crise adaptativa (Simon, 2005, p. 176).

Maria, mesmo satisfeita com a continuidade da relação, persistia insegura e ansiosa, expressando seu temor de perdê-lo. O curto período de rompimento da relação amorosa ainda durante a fase de entrevistas só fez recrudescer seu estado de insegurança. Seu parceiro, como já foi dito aqui, comandava outras funcionárias, sendo Maria a mais recente. Quando notou a proximidade e intimidade que ele compartilhava com uma antiga funcionária, seu ciúme transparecia. Sentia hostilidade contra a rival. Durante as sessões, inúmeras vezes enunciou sua vontade de agredi-la verbal e fisicamente. Em seu ciúme, sentia-a como uma ameaça, alguém que poderia tomar o amor que desejava e lhe era devido (Klein, 1957). Cabe dizer que, em sua história, a paciente experimentou situações de perdas reais que recordava com emoção. Quando tinha 10 anos, seu pai, a quem tanto amava, faleceu num acidente de trabalho. Adolescente, viu sua casa ser consumida pelas chamas, seguindo-se a isso a decadência econômica da família. Há 12 anos, sua mãe sucumbiu ao câncer; e fazia aproximadamente um ano que a paciente havia rompido casamento que durou 23 anos e cujas recordações preferia apagar. Experimentou um sentimento de posse de alguém e a angústia de logo perdê-lo. Klein e Riviere (1975, p. 122), referindo-se à escolha do parceiro amoroso em mulheres, afirmam: "as impressões que conserva do pai, os sentimentos que mantém para com ele admiração, confiança, e por aí afora - podem vir a desempenhar papel preponderante em sua escolha de um parceiro amoroso".

A paciente via em seu parceiro, 13 anos mais velho que ela, um pai idealizado - tal como o pai da infância e início da adolescência - que traria conforto, qualidade de vida e proteção. Mas o amado e dadivoso pai repentinamente faleceu, privando-a da segurança e proteção amorosa que desejava. Maria, inconscientemente, temia que o drama sentido pela perda real e súbita de seu pai fosse revivido no romance com seu parceiro atual. Assim, repentinamente, o parceiro também poderia privá-la do afeto 
que desejava. Quando o terapeuta apontou, por meio do recurso da interpretação teorizada e da cotransferência (Simon, 2005), à semelhança da experiência emocional vivida com seu pai da infância e com seu parceiro da maturidade, mudanças importantes ocorreram. Maria, que desde adolescente considerava-se "carente de um pai", compreendeu que via em seu parceiro a oportunidade de recuperar esse objeto perdido - o pai idealizado. Reconhecendo-se nessa interpretação, abriu-se a possibilidade de operar na paciente um discernimento entre situação passada e presente. Assim, passou a enxergar defeitos em seu parceiro que atenuaram a idealização. Reconheceu que ele nutria por ela uma ternura sincera, dissipando, pelos menos parcialmente, sua angústia de perdê-lo. Também pôde perceber seu ciúme e rivalidade a respeito dos quais ele tanto se queixava e que colocavam em risco a continuidade do romance. Conseguiu, enfim, ter maior controle sobre as próprias emoções, até porque estava se sentindo menos ameaçada.

Quanto à eficácia da adaptação, solucionada a crise, Maria permaneceu diagnosticada no grupo 2, adaptação ineficaz leve. O estado de insegurança e temor de rompimento iminente do romance progressivamente cedeu espaço a um sentimento de segurança e confiabilidade quanto à veracidade da ternura de seu parceiro, tanto quanto à possibilidade de continuidade do envolvimento amoroso. A paciente não havia afastado definitivamente de si a gama de pensamentos e sentimentos que povoavam seu psiquismo no início do tratamento. $\mathrm{Na}$ última sessão, confessou seu "medo" de um eventual insucesso do romance e sua irritação com as 'rivais'. Mas afirmou que esses sentimentos e pensamentos já não lhe causavam o mesmo incômodo e sofrimento de antes. De fato, Maria demonstrou maior capacidade de controlá-los, algo ressaltado por seu parceiro. Enfim, optou por deixar a relação como estava: mantendo os encontros às ocultas e desfrutando-os mais aliviada. Podemos conjecturar que a sujeição da paciente às condições do parceiro colocava-o a salvo de assumir um compromisso público pela relação, bem como deixá-lo livre para outras aventuras amorosas. Mas essa suposição terá de ser testada pela paciente.

\section{Consideraçóes finais}

Este artigo constituiu o relato sumário de um atendimento em Psicoterapia Breve
Operacionalizada, numa situação de crise por expectativa de perda. No caso da paciente atendida, em função do estado subjetivo que a dominava no momento em que foi procurar ajuda psicoterapêutica, com sua elevada expectativa ansiosa, poderia se esperar que a solução que encontraria para a problemática amorosa traria prejuízo para sua adaptação - como quando, para exemplificar, sentia impulsos para agredir suas rivais. A ajuda pontual e centrada na situação de crise por expectativa de perda auxiliou a paciente a desenvolver melhor autocontrole. Assim, não se precipitou numa atuação destrutiva, que poderia colocar em risco o envolvimento amoroso desejado. $\mathrm{Na} \mathrm{PBO}$ é fundamental que, diante de uma situação de crise, as intervenções do psicoterapeuta tenham como objetivo auxiliar o paciente a encontrar uma solução que não cause prejuízo para a adequação de sua adaptação. Para elucidar a importância do atendimento de situações de crise, Simon (2005, p. 143), concordando e citando Freud, coloca: "em estados de crise aguda a análise é para todos os intentos e propósitos inservível. O interesse total do ego é tomado pela dolorosa realidade e se retira da análise, que tenta ir além da superfície e descobrir as influências do passado". O psicoterapeuta, reconhecendo a imaturidade afetiva da paciente e utlizando-se da relação transferencial, em que representava a figura paterna, recorreu a "medidas suportivas" e sugeriu que ela deveria se esforçar em controlar seus impulsos hostis. Essa sugestão foi assimilada pela paciente, que adquiriu melhor autocontrole. Enquanto que a interpretação teorizada ajudou Maria a enxergar seu parceiro de maneira mais realista e menos idealizada e dissipar significativamente a angústia de perdê-lo. Ambas intervenções terapêuticas, centradas na situação crítica, contribuíram para que a paciente encontrasse uma solução para sua crise, mantendo o envolvimento amoroso que desejava. Nesse sentido, o arsenal conceitual e instrumental constitutivo da EDAO e da PBO demonstrarou relevante importância na prática da psicoterapia breve, uma vez que ofereceu ao psicoterapeuta meios de identificar e atuar com eficiência em situações de crise por expectativa de perda.

Cabe ressaltar que esse artigo é fruto dos estudos realizados pelo Grupo de Pesquisa em Psicologia Preventiva e Psicoterapia Breve Operacionalizada, que é coordenado pelo prof. titular Ryad Simon e pela profa. Dra. Kayoko Yamamoto. 
Trata-se de uma pesquisa em andamento e cujo objetivo principal é verificar a eficiência terapêutica da Psicoterapia Breve Operacionalizada. Tal foi a intenção deste artigo.

\section{Agradecimento}

Conselho Nacional de Desenvolvimento Científico e Tecnológico - CNPq.

\section{Referências}

Altman, M., Yamamoto, K., \& Tardivo, L. (2007). Psicoterapia breve operacionalizada com pessoas idosas. Mudanças: Psicologia da Saúde, 15(2), 135-144.

Alves, H. (2001). Psicoterapia Breve Operacionalizada PBO com adolescentes da rede pública escolar da cidade de Santos - SP: Uma contribuição à psicologia clínica preventiva. Tese de Doutorado, Instituto de Psicologia, Universidade de São Paulo, São Paulo.

Bellak, L., \& Small, L. (1980). Psicoterapia de emergência e psicoterapia breve. Porto Alegre: Artes Médicas.

Caplan, G. (1980). Princípios de Psiquiatria Preventiva. Rio de Janeiro: Zahar.

Erikson, E. H. (1959). Identity and life cycle. New York: International University Press.

Faundes, A., Rosas, F., Bedone, A. J., \& Orozco, L. T. (2006). Violência sexual: Procedimentos indicados e seus resultados no atendimento de urgência de mulheres vítimas de estupro. Revista Brasileira de Ginecologia e Obstetrícia, 28(2), p. 126-135.

Gebara, A.C. (2003). Como interpretar na psicoterapia breve psicodinâmica. São Paulo: Vetor.

Klein, M., \& Riviere, J. (1975). Amor, ódio e reparação. São Paulo: EDUSP.

Klein, M. (1957). Inveja e gratidão. Rio de Janeiro: Imago, 1991.

Leavell,H.R., \& Clark, E. G. (1965). Preventive Medicine for the doctor in his Community. New York: McGraw-Hill.
Malan, D. (1976). As fronteiras da psicoterapia breve. Porto Alegre: Artes Médicas.

Moffatt, A. (1982). Terapia de crise. São Paulo: Cortez.

Oliveira, E. P. (2001). Eficácia da psicoterapia breve operacionalizada com pacientes com hipertensão essencial. Mudanças: Psicologia da Saúde, 9(16), 64-85.

Sifneos, (1989). Psicoterapia dinâmica breve: Avaliação e técnica. Porto Alegre: Artes Médicas.

Sifneos, P. E. (1993). Psicoterapia breve provocadora de ansiedade. Porto Alegre: Artes Médicas.

Simon, R. (1989). Psicologia Clínica Preventiva: Novos fundamentos. São Paulo: EPU.

Simon, R. (1996). Do diagnóstico à psicoterapia breve. Jornal Brasileiro de Psiquiatria, 445(7), 403-408.

Simon, R. (1998). Proposta de redefinição da Escala Diagnóstica Adaptativa. Mudanças: Psicologia da Saúde, 10(9), 13-26.

Simon, R. (2001). Manejo da transferência e da contratransferência na psicoterapia psicanalítica. Trabalho apresentado no $5^{\circ}$ Encontro do Curso de Especialização em Psicoterapia Psicanalítica, Universidade de São Paulo, São Paulo.

Simon, R. (2005). Psicoterapia breve operacionalizada: Teoria e técnica. São Paulo: Casa do Psicólogo.

Simon, R., \& Yamamoto, K. (2008). Psicoterapia breve operacionalizada em situação de crise adaptativa. Mudanças: Psicologia da Saúde, 16(2), 144-151.

Wolberg,L.R.(1967). The Technique of Psychotherapy. New York: Grune \& Stratton.

Recebido: 06/04/2009

Received: 04/06/2009

Aprovado: 04/08/2009

Approved: 08/04/2009 